\title{
ASSESSMENT OF PULMONARY FUNCTION AND CLINICAL FEATURES, AND THEIR COMPARISON BETWEEN OBESE AND NON-OBESE PATIENTS OF BRONCHIAL ASTHMA
}

\author{
Akshay M. Hiremath', Adheep B. Amberker², Shanu Saleem ${ }^{3}$
}

${ }^{1}$ Assistant Professor, Department of Respiratory Medicine, Jagadguru Jayadeva Murugarajendra Medical College, Davangere, Karnataka, India. ${ }^{2}$ Assistant Professor, Department of Respiratory Medicine, Jagadguru Jayadeva Murugarajendra Medical College, Davangere, Karnataka, India. ${ }_{3}^{3}$ Postgraduate Student, Department of Respiratory Medicine, Jagadguru Jayadeva Murugarajendra Medical College, Davangere, Karnataka, India.

\section{ABSTRACT}

\section{BACKGROUND}

Asthma is a heterogeneous disease, usually characterized by chronic inflammation. It is characterised by history of respiratory symptoms such as wheeze, shortness of breath, chest tightness and cough that vary over time and in intensity, together with variable expiratory airflow limitation. ${ }^{1}$ Obesity may be defined as an abnormal growth of the adipose tissue due to an enlargement of fat cell size or an increase in fat cell number or both. ${ }^{2}$ Asthma with obesity is one of the phenotypes of asthma where patients will have multiple consequences related to excess adipose tissue, including mechanical or physiologic effects on lung function and the airways as well as changes in the immune response and metabolic effects. Our study is a hospital based cross sectional observational study to assess the pulmonary function, clinical profile and its correlation between obese and non-obese bronchial asthmatic patients.

\section{METHODS}

This was an observational study of stable obese and non-obese bronchial asthma patients undergoing pulmonary function test on inpatient or outpatient basis in Department of Pulmonary Medicine, J.J.M. Medical College, Davangere. The study was carried out on 100 patients with bronchial asthma (50 obese and 50 non-obese patients). Detailed history was obtained, physical examination was done along with correlation of pulmonary function and clinical profile. Sample size was taken for convenience.

\section{RESULTS}

In this study, out of 100 patients 55\% were males, and $45 \%$ were females with higher total cholesterol and triglycerides in obese asthmatics compared to non-obese asthmatics. The most common symptoms were breathlessness followed by cough and wheeze. In this study, it was found that breathlessness, cough, wheeze are more common in obese asthmatics than non-obese asthmatics. There was significant difference of waist circumference (W.C.), hip circumference (H.C.) and waist to hip ratio (W.H.R.) between obese and non-obese asthmatics. Hypertension and diabetes mellitus more prevalent in obese group than non-obese. FVC, FEV1, and FEF25-75 \% values were reduced in obese asthmatics compared to non-obese asthmatics in contrast to FEV1/FVC which was higher in obese asthmatics compared to non-obese asthmatics. It was observed that increased in BMI causes impaired pulmonary function.

\section{CONCLUSIONS}

The increasing prevalence of asthma and obesity has suggested an association between the two. The most common symptoms observed in this study were breathlessness, cough and wheeze. PR (Pulse Rate) SBP (Systolic Blood Pressure), DBP (Diastolic Blood Pressure), RR (Respiratory Rate), TLC (Total Leucocyte Count), AEC (Absolute Eosinophil Count), LP (Lipid Profile) were higher in obese asthmatics. Diabetes mellitus and hypertension were more prevalent in obese asthmatics. FVC, FEV1 are decreased in obese asthmatics but the amount of reversibility is more for non-obese asthmatics. It was also observed that increased BMI causes impaired pulmonary function.

\section{KEY WORDS}

PFT- Pulmonary Function Test, FEV1- Forced Expiratory Volume in $1^{\text {st }}$ Second, FVC- Forced Vital Capacity, BMI- Body Mass Index, WC- Waist Circumference, HC- Hip Circumference, WHR- Waist Hip Ratio, AEC- Absolute Eosinophil Count

HOW TO CITE THIS ARTICLE: Hiremath AM, Amberker AB, Saleem S. The study to assess the pulmonary function, clinical profile and its correlation between obese and non-obese bronchial asthmatic patient. J. Evolution Med. Dent. Sci. 2019;8(29):2355-2361, DOI: $10.14260 /$ jemds/2019/516

\section{BACKGROUND}

Asthma is defined as a clinical syndrome characterized by airway inflammation, variable lung function and airway's hyper-responsive-ness. The rate of asthma increases as communities adopt western lifestyles and become urbanized

'Financial or Other Competing Interest': None.

Submission 24-05-2019, Peer Review 03-07-2019,

Acceptance 10-07-2019, Published 22-07-2019.

Corresponding Author:

Dr. Akshay M. Hiremath,

No. 355, Gangadhareshwara Krupa,

$1^{\text {st }}$ Main S Nijalingappa Layout,

Davangere-577004, Karnataka, India.

E-mail: akshaymh03@gmail.com

DOI: $10.14260 /$ jemds/2019/516 and with the projected increase in the urban population it is estimated that there may be an additional 100 million persons with asthma by 2025 in the world. The number of disabilityadjusted life years (DALYs) lost due to asthma (15 million per year) is similar to that for diabetes, cirrhosis of the liver, or schizophrenia. ${ }^{3}$ Factors influencing the development and expression of asthma includes host factors like genetic, obesity, sex and environmental factors like allergens, infections, occupational sensitizers, tobacco smoke, outdoor and indoor pollution, diet. Airflow limitation in asthma is recurrent and caused by a variety of changes in the airway, these include-

1. Bronchoconstriction: Allergen-induced acute bronchoconstriction results from an IgE-dependent release of mediators from mast cells that includes histamine, 
tryptase, leukotrienes, and prostaglandins that directly contract airway smooth muscle leading to clinical symptoms of asthma.

2. Airway Oedema: Persistent inflammation leads to airway edema, inflammation, mucus hyper-secretion and the formation of inspissated mucus plugs, as well as structural changes including hypertrophy and hyperplasia of the airway smooth muscles.

3. Airway Hyper-Responsiveness: Airway hyperresponsiveness an exaggerated broncho-constrictor response to a wide variety of stimuli, the mechanisms influencing airway hyper-responsiveness are multiple and include inflammation, dysfunctional neuroregulation, and structural changes.

4. Airway Remodeling: Permanent structural changes like thickening of the sub-basement membrane, sub epithelial fibrosis, airway smooth muscle hypertrophy and hyperplasia, blood vessel proliferation and dilation, and mucous gland hyperplasia and hyper secretion can occur in the airway and are associated with a progressive loss of lung function, airflow obstruction and airway responsiveness and render the patient less responsive to therapy.

Obesity is an increasingly important health problem worldwide including the developing countries. In India obesity is emerging as an important health problem particularly in urban areas paradoxically co-existing with under nutrition. Increasing rates of obesity have paralleled increasing rates in asthma prevalence but the interrelation is uncertain ${ }^{4}$.The etiology of obesity is complex, and is one of multiple causation. Obesity can occur at any age, and generally increases with age. Infants with excessive weight gain have increased incidence of obesity in later life. Women generally have higher rate of obesity than men, although men may have higher rates of overweight. There is convincing evidence that regular physical activity is protective against unhealthy weight gain. Whereas sedentary lifestyle particularly sedentary occupation and inactive recreational activities promotes it. There is a clear inverse relationship between socioeconomic status and obesity. The composition of the diet, the periodicity with which food is eaten and the amount of energy derived from it are all relevant to the etiology of obesity: A recent review of studies concluded that the relationship between alcohol consumption and adiposity was generally positive for men and negative for women. Obesity frequently run in families, but this is not necessarily explained solely by the influence of genes. Some endocrine disorders like Cushing's syndrome, growth hormone deficiency have associated obesity. Reports that use of tobacco lowers body weight began to appear more than 100 years ago, but detailed studies have been reported only during the past 10 years or so. Use of certain drugs, e.g. corticosteroids, contraceptives, insulin etc. can promote weight gain $^{5}$. Obesity is associated with systemic inflammation, which may result in airway hyper-reactivity, which is observed in asthmatic individuals ${ }^{6}$. Visceral adipose tissue is the key factor in the formation of low-grade chronic inflammation in obese individuals ${ }^{7}$ and plays a role in remodelling, which is characteristic of asthma. High levels of interleukin-6 (IL-6) and tumour necrosis factor-alpha (TNF- $\alpha$ ) are observed in individuals with visceral obesity, which exacerbates the inflammatory response. ${ }^{8}$ Obesity, even in the absence of intrinsic lung disease, causes physiologic impairment in lung function due to mass-loading of the respiratory system ${ }^{9}$. Three Body mass index (BMI), Waist circumference (WC) and Waist-to-hip circumference ratio (WHR) are the simple measures of obesity which are widely used in clinical practice. Obesity is considered above $30 \mathrm{~kg} / \mathrm{m}^{2}$ according to WHO classification of BMI, (table 1) whereas for Indian population obesity is considered above $23 \mathrm{~kg} / \mathrm{m}^{2}$ according to WHO Asia Pacific perspective for Asians (WHO IOTF 2003)(table 2). Waist circumference more than $90 \mathrm{cms}$ (Men), more than $80 \mathrm{cms}$ (Women) are at high risk of metabolic complications. ${ }^{10}$ and reflects changes in risk factors cardiovascular disease and other chronic diseases; waist hip ratio (WHR) more than 1 in men and more than 0.85 in women indicates abdominal fat accumulation. With reference to table 1 , obesity is considered above $30 \mathrm{~kg} / \mathrm{m}^{2}$ according to WHO classification of BMI, whereas for Indian population obesity is considered above $23 \mathrm{~kg} / \mathrm{m}^{2}$ according to WHO Asia Pacific perspective for Asians (WHO IOTF 2003) shown in table 2. Obesity can lead to a reduction in pulmonary compliance, lung volumes, and the diameter of peripheral airways, and it can affect the volume of blood in the lungs and the ventilation perfusion relationship. Pulmonary compliance is reduced due to fat compression and infiltration of the thorax or the increase in lung blood volumes. Obesity can also lead to limitations in airflow, with reduction in both FEV1 and FVC11. Such changes in lung physiology lead to superficial respiration in obese patients, with a reduction in lung volumes, especially expiratory reserve volume. This reduction in lung volumes is associated with a reduction in the diameter of peripheral airways that can lead to changes in the function of bronchial smooth muscle. This in turn leads to a change in the actinmyosin cross-bridge cycle, which can potentially increase both obstruction and bronchial hyper-reactivity (BHR). ${ }^{12}$ Comorbidities in obesity like dyslipidemia, gastro esophageal reflux disease (GERD), hypertension, obstructive sleep apnea and type 2 diabetes mellitus further aggravate asthma. ${ }^{13}$ Many studies on asthma in relation with obesity have been done in the world. These studies show decreased lung functions among obese asthmatics as well as increased morbidity and mortality pattern when compared to non-obese asthmatic patients. In India there are very few studies have been done on obese and non-obese asthmatics. Hence the present study was taken up, to compare differences in pulmonary function test, lipid profile, BMI (body mass index), clinical profile between obese and non-obese asthmatics.

We wanted to determine the baseline pulmonary function in obese and non-obese asthmatics using a computerized office spirometer (Vitalograph) and correlate the clinical and laboratory parameters with the pulmonary function.

\begin{tabular}{|c|c|c|}
\hline Classification & BMI $\left(\mathbf{K g} / \mathbf{m}^{\mathbf{2}}\right)$ & Risk of Comorbidities \\
\hline Underweight & Less than 18.5 & Low- but risk of other clinical problems increased \\
\hline Normal range & $18.5-24.9$ & Average \\
\hline Over weight & $>25$ & \\
\hline Pre obese & $25-29.9$ & Increased \\
\hline Obese class I & $30-34.9$ & Moderate \\
\hline Obese class II & $35-39.9$ & Severe \\
\hline Obese class III & $>40$ & Very severe \\
\hline \multicolumn{3}{|c|}{ Table 1. WHO Classification of BMI (2003). ${ }^{\mathbf{~}}$} \\
\hline
\end{tabular}




\begin{tabular}{|c|c|c|}
\hline Classification & BMI (kg/m2) & Risk of Comorbidities \\
\hline Underweight & $<18.5$ & Low \\
\hline Normal range & $18.5-22.9$ & Average \\
\hline Over weight & $>23$ & - \\
\hline At risk & $23-24.9$ & Increased \\
\hline Obese I & $25-29.9$ & Moderate \\
\hline Obese II & $>30$ & Severe \\
\hline Table 2. WHO Asia Pacific Perspective for Asians (WHO IOTF 2003) \\
\hline
\end{tabular}

\begin{tabular}{|c|c|c|c|c|c|c|}
\hline & \multicolumn{3}{|c|}{ Obese } & \multicolumn{3}{c|}{ Non-Obese } \\
\hline $\begin{array}{c}\text { PFT } \\
\text { Values }\end{array}$ & Predicted & Observed & $\begin{array}{c}\% \text { of } \\
\text { Observed } \\
\text { FVC }\end{array}$ & Predicted & Observed & $\%$ \\
\hline FVC & $2.44 \pm$ & $1.61 \pm$ & $66.87 \pm$ & 2.82 & $2.26 \pm$ & $79.76 \pm$ \\
& $0.49 \mathrm{l} / \mathrm{s}$ & $0.38 \mathrm{l} / \mathrm{s}$ & $13.69 \%$ & $\pm 0.731 / \mathrm{s}$. & $0.881 / \mathrm{s}$. & $22.04 \%$ \\
\hline \multirow{2}{*}{$\mathrm{FEV} 1$} & $2.10 \pm$ & $1.13 \pm$ & $55.04 \pm$ & $2.47 \pm$ & $1.50 \pm$ & $59.72 \pm$ \\
& 0.40. & 0.24 & $11.35 \%$ & 0.66 & 0.65. & $18.80 \%$ \\
\hline FEV1/ & $86.10 \pm$ & $70.40 \pm$ & $86.10 \pm$ & $87.08 \pm$ & $65.03 \pm$ & $87.08 \pm$ \\
FVC & 4.84 & 8.01 & $4.84 \%$ & 4.42 & 7.34. & $4.42 \%$ \\
\hline FEF & $3.20 \pm$ & $1.31 \pm$ & $42.23 \pm$ & $3.87 \pm$ & $1.59 \pm$ & $40.80 \pm$ \\
$(25-75)$ & 0.55 & 0.62 & $21.05 \%$ & 0.78 & 0.76 & $17.14 \%$ \\
\hline Table 3. Comparing PRE FVC, FEV1, FEV1/FVC, FEF (25-75) in Obese \\
\hline \multicolumn{7}{|c|}{ and Non-Obese Asthmatics } \\
\hline
\end{tabular}

\begin{tabular}{|c|c|c|c|c|}
\hline & \multicolumn{2}{|c|}{ Obese } & \multicolumn{2}{c|}{ Non-Obese } \\
\hline PFT Values & Observed & $\%$ of Observed & Observed & $\%$ of Observed \\
\hline FVC & $1.92 \pm 0.45 \mathrm{l} / \mathrm{s}$ & $79.58 \pm 13.83 \%$ & $2.56 \pm 0.80 \mathrm{l} / \mathrm{s}$. & $91.65 \pm 21.26 \%$ \\
\hline FEV1 & $1.47 \pm 0.33$ & $70.85 \pm 13.04 \%$ & $1.94 \pm 0.72$ & $78.20 \pm 21.26 \%$ \\
\hline FEV1/FVC & $77.07 \pm 7.92$ & - & $74.38 \pm 9.41$ & - \\
\hline FEF(25-75) & $1.93 \pm 0.68$ & $61.35 \pm 21.01 \%$ & $2.76 \pm 1.01$ & $71.92 \pm 24.00 \%$ \\
\hline \multicolumn{4}{|c|}{ Table 4. Comparing POST FVC, FEV1, FEV1/FVC, FEF (25-75) in Obese } \\
and Non-Obese Asthmatics \\
\hline
\end{tabular}

\section{METHODS}

Patients treated under Department of Pulmonary Medicine, attached to JJM Medical College, with bronchial asthma, fulfilling the inclusion \& exclusion criteria were included in the study after obtaining written informed consent. Demographic data, history, clinical examination and details of investigations like Pulmonary function test, Complete hemogram (Hemoglobin, Total leukocyte count and Differential leukocyte count), Chest X-ray (Postero-anterior view), Electrocardiogram, Lipid profile - Triglyceride, Total cholesterol, High density lipoprotein (HDL) and low density lipoprotein (LDL),Sputum AFB, Renal function test. Sample size taken for convenience.

\section{Source of Data}

The study was conducted in Department of Pulmonary Medicine, JJM medical college, Davangere, Karnataka on patients with Stable obese and non-obese Bronchial Asthma patients who were diagnosed with bronchial asthma as per GLOBAL Initiative for Asthma (GINA) guidelines ${ }^{1}$ undergoing pulmonary function test on inpatient or outpatient basis.

\section{Study Design}

A Hospital based cross sectional observational study.

\section{Place of Study}

JJM Medical College, Davangere.

\section{Duration of Study}

One year and six months (December 2014 - May 2016).

\section{Sampling Technique}

Convenient sampling.

\section{Ethical Issues}

The study was approved by the ethical and research committee of J. J. M. Medical College, Davangere. The selected patients were briefed about the study and written informed consent was obtained.

\section{Sample Size}

A total of 100 study subjects- 50 obese and 50 non-obese asthmatic adults. BMI $<22.9$ is taken as Non-Obese and $>23$ as Obese as per WHO Asia Pacific perspective for Asians (WHO IOTF 2003) ${ }^{10}$

\section{Inclusion Criteria}

1. All individuals above 18 years of age.

2. All adults diagnosed with Bronchial asthma as per GINA ${ }^{1}$ guidelines.

3. All asthmatic adults who are obese (which included at risk, Obese I and Obese II) and non-obese (underweight and normal) as per WHO Asian pacific perspective for Asians.

4. Patients who are willing to participate.

\section{Exclusion Criteria}

1 Unstable inpatients/out-patients. (i.e. Acute exacerbation of asthma)

2 Patients with chronic obstructive pulmonary disease, Bronchiectasis and other respiratory diseases.

3 Patients with malignancies, cardiac complications or neuromuscular diseases.

4 Post-operative patients, individuals with serious systemic illnesses like chronic renal failure or complicated diabetes mellitus etc.

\section{Statistical Methods}

Data was entered in Microsoft excel and analyzed using EPI INFO version 6 software. Descriptive statistics like proportions, percentages and standard deviation are used. For comparison between the groups chi square test, Independent ' $\mathrm{t}$ ' test, ANOVA were used. $\mathrm{P}$ value of less than 0.05 is considered as statistically significant.

\section{RESULTS}

\section{1) Demographic Data}

A total of 100 bronchial asthma patients diagnosed as per GINA guidelines were taken up for the study. Out of 100 patients, 50 were obese bronchial asthma patients $(n=25)$ and remaining 50 were non-obese bronchial asthma patients $(n=25)$. In this study of 100 patients, the age of patients ranged from 20-59 years, the age of patients in obese group ranged from 28-59 years with a mean of $40.27 \pm 8.395$ years, in nonobese group it ranged from 20-50 years with a mean of $32.57 \pm 7.583$ years. Out of total 100 asthmatic patients studied, in obese asthmatic group 18 (36.6\%) were male patients and $32(63.4 \%)$ were female patients and in non-obese asthmatic group $36(73.3 \%)$ were males and $14(26.7 \%)$ were females. The association between the groups is statistically significant. $(\mathrm{p}=0.009)$

\section{2) Anthropometry}

a) Height- The height of the patients in obese group ranged from 140 to $170 \mathrm{cms}$ and the mean value is $155.33 \pm 8.066 \mathrm{cms}$. Non obese were taller compared to obese asthmatics but there is no statistical difference of height between the two groups. $(\mathrm{p}=0.075)$ 
b) Weight- The weight of the patients in the obese group ranged from 53 to 109 kilograms with a mean of $72.53 \pm$ 12.822 kilograms. The weight of the patients in the non-obese group ranged from 40 to 70 kilograms with a mean of $54.13 \pm$ 9.464 kilograms. The difference between the two groups is statistically significant. $(\mathrm{p}=<0.0001)$.

c) BMI- The BMI of the patients in the obese group ranged from 23.4 to $48.4 \mathrm{~kg} / \mathrm{m}^{2}$ and the mean value for the group is 30.16 $\pm 4.63 \mathrm{~kg} / \mathrm{m}^{2}$. The BMI of the patients in the non-obese group ranged from 15.15 to $22.86 \mathrm{~kg} / \mathrm{m}^{2}$ and the mean value for this group is $20.55 \pm 2.689 \mathrm{~kg} / \mathrm{m}^{2}$ and the difference between these groups is found to be statistically significant $(\mathrm{p}=<0.0001)$.

\section{Symptoms}

a) Cough- In this study of 100 patients cough is more among non-obese compared to obese asthmatics, and the association is found to be statistically significant. $(p=<0.05)$

b) Breathlessness- In this study of 100 patients, breathlessness is present in all 50 obese asthmatics and 45 non-obese asthmatics, the difference between groups is not statistically significant.

c) Wheeze- Of the total 100 asthmatic patients studied, obese asthmatics $(60 \%)$ have more wheeze compared to non-obese asthmatics (53.4\%), there is no statistical significance.

d) Seasonal Variation- Of the total 100 asthmatic patients, seasonal variation is more among non-obese (66.6\%) compared to obese asthmatics (40\%). Significant association is seen among the groups.

\section{4) Past History}

a) Atopy- Of the total 100 asthmatic patient's history of atopy is found to be more among non-obese asthmatics (56.6\%) compared to obese asthmatics (33.3\%). There is no statistical significance between the groups.

b) Bronchial Asthma- Out of 100 patients studied, 20 obese asthmatics and 10 non obese asthmatics had previous history of asthma.

\section{5) Comorbid Conditions}

a) Hypertension- Out of 100 patients studied, 15 (30\%) obese asthmatics and $4(6.66 \%)$ non obese asthmatics had previous history of hypertension. There was significant association seen between the groups $(\mathrm{p}=0.02)$

b) Diabetes Mellitus- Out of 100 patients studied, $23.3 \%$ obese asthmatics and $6.66 \%$ non-obese asthmatics had previous history of diabetes mellitus.

\section{6) Vitals}

a) Pulse Rate- The mean value of pulse rate among the patients in obese group is $90.8 \mathrm{bpm}$ and in non-obese group is 77.07 bpm respectively. The student $t$ test observed that this variable between the groups is statistically significant. $(\mathrm{p}=<0.0001)$

b) SBP- The mean systolic blood pressure in obese group and non-obese group is $129.2 \mathrm{~mm} \mathrm{Hg}$ and $118 \mathrm{~mm} \mathrm{Hg}$ respectively. The student $t$ test observed that this variable between the groups is statistically significant. $(\mathrm{p}=<0.0001)$

c) DBP- The mean diastolic blood pressure in obese group and non-obese group is $83.53 \mathrm{~mm} \mathrm{Hg}$ and $77.93 \mathrm{~mm} \mathrm{Hg}$ respectively. The student $t$ test observed that this variable between the groups is statistically significant. $(p=0.001)$ d) Respiratory rate- The mean respiratory rate in obese group and non-obese group is 17.4 cycles per minute and 16.33 cycles per minute respectively. The student $t$ test observed that this variable between the groups is statistically significant $(\mathrm{p}=<0.0001)$.

\section{7) Complete Hemogram}

a) Haemoglobin- The mean value of haemoglobin for obese group is $13.5 \mathrm{gm} / \mathrm{dl}$ with standard deviation of 0.99 . The mean value of haemoglobin for non-obese group is $13.96 \mathrm{gm} / \mathrm{dl}$ with standard deviation of 1.31. The student $t$ test applied found that the difference of variable between the groups is not statistically significant.

b) Total Leukocyte Count- The mean value of Total leukocyte count for obese group is 10,600 cells $/ \mathrm{mm}^{3}$ with standard deviation of 2381.05. The mean value of total leukocyte count for non-obese group is 9310 cells $/ \mathrm{mm}^{3}$ with standard deviation of 1835.59. The student $t$ test applied found that the difference of variable between the two groups is statistically significant. $(\mathrm{p}=0.025)$.

c) Neutrophils- The mean value of neutrophil for obese group is $67.53 \%$ with standard deviation of 10.38 . The mean value of neutrophil for non-obese group is $66.9 \%$ with standard deviation of 10.29. The student $t$ test applied found that the difference of variable between the groups is not statistically significant.

d) Monocytes- The mean value of monocytes for obese group is $6.77 \%$ with standard deviation of 2.27 . The mean value of monocytes for non-obese group is $7.57 \%$ with standard deviation of 1.98. The student $t$ test applied found that the difference of variable between the groups is not statistically significant.

e) Eosinophils- The mean value of eosinophils for obese group is $4.27 \%$ with standard deviation of 2.72 . The mean value of eosinophils for non-obese group is $5.43 \%$ with standard deviation of 3.89. The student t test applied found that the difference of variable between the groups is not statistically significant.

f) Lymphocytes- The mean value of lymphocytes for obese group is $20.3 \%$ with standard deviation of 8.61 . The mean value of lymphocytes for non-obese group is $16.47 \%$ with standard deviation of 8.42. The student $t$ test applied found that the difference of variable between the groups is not statistically significant.

g) Basophils- The mean value of basophils for obese group is $0.2 \%$ with standard deviation of 0.41 . The mean value of basophils for non-obese group is $0.43 \%$ with standard deviation of 0.68 .

h) AEC (cells $/ \mathrm{mm}^{3}$ )- The mean value of absolute eosinophil count for obese group is 449.5 cells $/ \mathrm{mm}^{3}$ with standard deviation of 246.16. The mean value of Absolute eosinophil count for non-obese group is 600.72 cells $/ \mathrm{mm}^{3}$ with standard deviation of 300.96 . There was significant difference between the groups $(\mathrm{p}=0.05)$

\section{8) Lipid Profile}

a) Total Cholesterol- The mean value of Total cholesterol for the obese group is $201.97 \pm 32.41 \mathrm{mg} / \mathrm{dl}$. The mean value of total cholesterol for the non-obese group is $172.27 \pm 25.03$ $\mathrm{mg} / \mathrm{dl}$. There is significant difference of this variable between obese and non-obese asthmatics $(\mathrm{p}=<0.001)$. 
b) Triglycerides- The mean value of triglycerides for the obese group is $147.48 \pm 61.00 \mathrm{mg} / \mathrm{dl}$. The mean value of triglycerides for the non-obese group is $115.13 \pm 40.01 \mathrm{mg} / \mathrm{dl}$. There is significant difference of this variable between obese and nonobese asthmatics. ( $\mathrm{p}=0.02)$.

c) HDL- The mean value of HDL for the obese group is 43.46 $\pm 11.47 \mathrm{mg} / \mathrm{dl}$. The mean value of HDL for the non-obese group is $48.77 \pm 11.96 \mathrm{mg} / \mathrm{dl}$. There is no significant difference of this variable between obese and non-obese asthmatics.

d) LDL- The mean value of LDL for the obese group is $114.12 \pm 32.74 \mathrm{mg} / \mathrm{dl}$. The mean value of LDL for the non-obese group is $111.04 \pm 34.44 \mathrm{mg} / \mathrm{dl}$. There is no significant difference of this variable between obese and non-obese asthmatics.

e) VLDL- The mean value of VLDL for the obese group is 31.36 $\pm 11.90 \mathrm{mg} / \mathrm{dl}$. The mean value of VLDL for the non-obese group is $27.16 \pm 7.74 \mathrm{mg} / \mathrm{dl}$. There is no significant difference of this variable between obese and non-obese asthmatics.

\section{9) Spirometric Values}

a) FVC- The mean value of predicted FVC for the obese group is $2.44 \pm 0.49 \mathrm{l} / \mathrm{s}$ and mean value of predicted FVC for the nonobese group is $2.82 \pm 0.73 \mathrm{l} / \mathrm{s}$. The student $\mathrm{t}$ test applied found that the difference between the two groups for this variable is statistically significant. ( $p=0.023)$. The mean value of observed FVC for the obese group is $1.61 \pm 0.38 \mathrm{l} / \mathrm{s}$ and mean value of observed FVC for the non-obese group is $2.26 \pm 0.88 \mathrm{l} / \mathrm{s}$. The difference between the two groups is statistically significant. $(p=0.001)$. Percentage of Observed FVC in obese and nonobese asthmatics is $66.87 \pm 13.69 \%$ and $79.76 \pm 22.04 \%$ respectively. The mean value of post FVC for the obese group is $1.92 \pm 0.45 \mathrm{l} / \mathrm{s}$ and mean value of post FVC for the non-obese group is $2.56 \pm 0.80 \mathrm{l} / \mathrm{s}$. The difference between the two groups is statistically significant. $(\mathrm{p}=<0.0010)$. Percentage of Post FVC in obese and non-obese asthmatics is $79.58 \pm 13.83$ $\%$ and $91.65 \pm 21.26 \%$ respectively. The mean value of predicted FVC for at risk, obese I and obese II groups are 2.66 $\pm 0.28 \mathrm{l} / \mathrm{s}, 2.48 \pm 0.47 \mathrm{l} / \mathrm{s}$ and $2.35 \pm 0.55 \mathrm{l} / \mathrm{s}$ respectively. The mean value of Observed FVC for the at risk, obese I and obese II groups are $1.80 \pm 0.17 \mathrm{l} / \mathrm{s}, 1.61 \pm 0.30 \mathrm{l} / \mathrm{s}$ and $1.58 \pm 0.49 \mathrm{l} / \mathrm{s}$ respectively. Percentage of Observed FVC in at risk, obese I, obese II asthmatics is $68.50 \pm 13.51 \%, 66.39 \pm 12.90 \%, 67.23$ $\pm 15.80 \%$ respectively. Post FVC for at risk group, obese I and obese II is $2.01 \pm 0.13 \mathrm{l} / \mathrm{s}, 1.96 \pm 0.44 \mathrm{l} / \mathrm{s}, 1.87 \pm 0.52 \mathrm{l} / \mathrm{s}$ respectively. Percentage of Post FVC in at risk, obese I, obese II asthmatics is $76.37 \pm 12.73 \%, 79.90 \pm 13.84 \%, 79.69 \pm 15.05$ $\%$ respectively. The difference of Observed FVC and Post FVC between all three obese asthmatics group is statistically significant. FVC was decreased in Obese II asthmatics compared to at risk and obese I asthmatics.

b) FEV1- The mean value of predicted FEV1 for the obese group is $2.10 \pm 0.40$ and mean value of predicted $\mathrm{FEV}_{1}$ for the non-obese group is $2.47 \pm 0.66$. The difference of predicted FEV1 between the groups is statistically significant. $(p=0.01)$. The mean value of observed $\mathrm{FEV}_{1}$ for the obese group is $1.13 \pm$ 0.24 and mean value of observed $\mathrm{FEV}_{1}$ for the non-obese group is $1.50 \pm 0.65$. The difference between the two groups is statistically significant. ( $\mathrm{p}=0.006)$. Percentage of Observed FEV 1 in obese and non-obese asthmatics is $55.04 \pm 11.35 \%$ and $59.72 \pm 18.80 \%$ respectively. The mean value of post $\mathrm{FEV}_{1}$ for the obese group is $1.47 \pm 0.33$ and mean value of post FEV for the non-obese group is $1.94 \pm 0.72$. The difference between the groups is statistically significant. $(\mathrm{p}=0.002)$. Percentage of Post FEV 1 in obese and non-obese asthmatics is $70.85 \pm 13.04$ $\%$ and $78.20 \pm 21.26 \%$ respectively. The mean value of predicted FEV1 for at risk group, obese I and obese II is $2.27 \pm$ $0.18 \mathrm{l} / \mathrm{s}, 2.15 \pm 0.40 \mathrm{l} / \mathrm{s}, 2.00 \pm 0.43 \mathrm{l} / \mathrm{s}$ respectively. The mean value of Observed FEV1 for at risk group, obese I and obese II is $1.29 \pm 0.13 \mathrm{l} / \mathrm{s}, 1.12 \pm 0.22 \mathrm{l} / \mathrm{s}, 1.13 \pm 0.27 \mathrm{l} / \mathrm{s}$ respectively. The difference of Observed FEV1 between the sub-groups is statistically significant. Percentage of Observed FEV1 in at risk, obese I, obese II asthmatics is $57.24 \pm 10.24 \%, 53.40 \pm 12.22$ $\%, 56.86 \pm 10.88 \%$ respectively. Post FEV1 for the at-risk group, obese I and obese II is $1.69 \pm 0.18 \mathrm{l} / \mathrm{s}, 1.48 \pm 0.33 \mathrm{l} / \mathrm{s}$, $1.41 \pm 0.35 \mathrm{l} / \mathrm{s}$ respectively. The difference of post FEV1 between the sub-groups is statistically significant. Percentage of Post FEV1 in at risk, obese I, obese II asthmatics is $75.02 \pm$ $14.18 \%, 70.09 \pm 13.51 \%$, and $71.16 \pm 13.30 \%$ respectively. c) FEV1/FVC- The mean value of predicted FEV1/FVC for the obese group is $86.10 \pm 4.84$ and mean value of predicted FEV1/FVC for the non-obese group is $87.08 \pm 4.42$. The student $t$ test applied found that the $\mathrm{p}$ value between the two groups for this variable is not statistically significant. The mean value of observed FEV1/FVC for the obese group is 70.40 \pm 8.01 and mean value of observed FEV1/FVC for the nonobese group is $65.03 \pm 7.34$. The student $t$ test applied found that the $\mathrm{p}$ value between the two groups for this variable is statistically significant. $(p=0.009)$ The mean value of post FEV1/FVC for the obese group is $77.07 \pm 7.92$ and mean value of post FEV1/FVC for the non-obese group is $74.38 \pm 9.41$. The student $t$ test applied found that the $p$ value between the groups for this variable is not statistically significant. The mean value of predicted FEV1/FVC for at risk, obese I, obese II is $85.56 \pm 2.03 \%, 86.62 \pm 4.68 \%$ and $85.49 \pm 5.53 \%$ respectively. The mean value of observed FEV1/FVC for at risk, obese I, obese II is $70.35 \pm 1.52 \%, 69.62 \pm 7.85 \%$ and $71.45 \pm$ $9.09 \%$ respectively. The mean value of post FEV1/FVC for at risk, obese I, obese II is $83.96 \pm 3.83 \%, 76.89 \pm 7.99 \%$ and $76.17 \pm 8.20 \%$ respectively.

d) FEF 25-75\%- The mean value of Predicted FEF 25-75 for the obese group is $3.20 \pm 0.55$ and mean value of Predicted FEF $25-75$ for the non-obese group is $3.87 \pm 0.78$. The student t test applied found that the $p$ value between the two groups for this variable is statistically significant. $(p=<0.0010)$. The mean value of observed FEF $25-75$ for the obese group is $1.31 \pm 0.62$ and mean value of observed FEF 25-75 for the non- obese group is $1.59 \pm 0.76$. The student $t$ test applied found that the $\mathrm{p}$ value between the two groups for this variable is not statistically significant. Percentage of observed FEF 25-75 in obese and non-obese asthmatics is $42.23 \pm 21.05 \%$ and 40.80 $\pm 17.14 \%$ respectively. The mean value of post FEF25-75 for the obese group is $1.93 \pm 0.68$ and mean value of post FEF 25 75 for the non-obese group is $2.76 \pm 1.01$. The student $t$ test applied found that the $\mathrm{p}$ value between the two groups for this variable is statistically significant. $(\mathrm{p}=<0.0010)$. Percentage of Post FEF 25-75 in obese and non-obese asthmatics is $61.35 \pm$ $21.01 \%$ and $71.92 \pm 24.00 \%$ respectively. The mean value of Predicted FEF 25-75 for at risk, obese I and obese II is 3.71 \pm $0.19 \mathrm{l} / \mathrm{s}, 3.26 \pm 0.58 \mathrm{l} / \mathrm{s}$ and $3.03 \pm 0.52 \mathrm{l} / \mathrm{s}$ respectively. The mean value \pm SD of Observed FEF $25-75$ for at risk, obese I and obese II is $1.81 \pm 0.91 \mathrm{l} / \mathrm{s}, 1.24 \pm 0.56 \mathrm{l} / \mathrm{s}$ and $1.31 \pm 0.69 \mathrm{l} / \mathrm{s}$ respectively. Percentage of observed FEF $25-75$ in at risk, obese I and obese II is $48.15 \pm 22.14 \%, 39.72 \pm 19.48 \%$ and $44.58 \pm 24.17 \%$ respectively. The mean value \pm SD of post 
FEF25-75 for at risk, obese I and obese II is $2.60 \pm 0.87 \mathrm{l} / \mathrm{s}, 1.99$ \pm 0.57 and $1.73 \pm 0.76$. The difference of Post FEF 25-75 between the subgroups is statistically significant.Percentage of Post FEF 25-75 in at risk, obese I and obese II is $69.53 \pm$ $19.89 \%, 62.67 \pm 18.37 \%$ and $58.22 \pm 25.34 \%$ respectively.

\section{E) Bronchodilator Response}

The mean percentage change in reversibility of spirometric values in non-obese population is $34.07 \%$ whereas in obese population it is $29.24 \%$. The student $t$ test applied found that the $\mathrm{p}$ value between the groups for this variable is not statistically significant. $(\mathrm{p}=0.23776)$ Bronchodilator response is found to be more in non-obese asthmatic group compared to obese asthmatics, however it was not statistically significant.

\section{DISCUSSION}

In this study of 100 patients with bronchial asthma, the age of patients ranged from 20-59 years, the mean age of patients in obese group was $40.27 \pm 8.395$ years, in non-obese group was $32.57 \pm 7.583$ years. Nearly two thirds in obese group were female and male in non-obese group. The mean weight of the patients in the obese group was $72.53 \pm 12.822 \mathrm{kgs}$. and in the non-obese group with a mean of $54.13 \pm 9.464$ kgs. CastroRodriguez et al.,14 (2001) demonstrated that girls becoming overweight or obese between 6 and 11 years of age had increased odds of developing new asthma symptoms. The mean BMI of the patients in the obese group was $30.16 \pm 4.63$ kilograms/metre ${ }^{2}$ and in the non-obese group was $20.55 \pm$ $2.689 \mathrm{~kg} / \mathrm{m}^{2}$. The study findings is similar to the study done by Dosi R et al. ${ }^{15}$

Beuther et al $^{16}$ (2007) have demonstrated a clear doseresponse relationship between BMI and asthma, suggesting that asthma risk increases further as body weight increases. In addition, he had shown that the odds of incidence of asthma in overweight and obese men and women were similar. Most common symptom in both groups was breathlessness which was present in all patients in obese group and $90 \%$ of nonobese group, which was followed by cough and wheeze. The present study showed significant association of cough and seasonal variation between obese and non-obese asthmatic patients as comparable with the study done by Aruna G et al. ${ }^{17}$ The presence of comorbid condition like diabetes and hypertension was more common in obese compared to nonobese which was consistent with the study by Pakhale $\mathrm{S}$ et al. ${ }^{18}$ (2010).Our study shows there is significant difference of Absolute eosinophil count between the groups. $(\mathrm{p}=0.05)$ but it was contrast with the finding of the study done by Aruna G et al. The mean of Forced expiratory volume in 1st second (FEV1) and Forced vital capacity (FVC), in obese asthmatics is $1.13 \pm$ $0.24 \mathrm{l} / \mathrm{s}$ and $1.61 \pm 0.38 \mathrm{l} / \mathrm{s}$ respectively and in non-obese it is $1.50 \pm 0.65 \mathrm{l} / \mathrm{s}$ and $2.26 \pm 0.88 \mathrm{l} / \mathrm{s}$. In the present study FEV1, FVC is lower in obese asthmatics compared to non-obese asthmatics which is comparable with the studies done by Pakhale s et al. (2010) Dosi R et al, Razi et al. ${ }^{19}$

The mean percentage change of reversibility in spirometric values (FEV1) among non-obese population is $34.07 \%$, whereas in obese population it is $29.24 \%$. but was not statistically significant. ( $\mathrm{p}=0.23776)$ which was in contrast with the study done by Sharma L, et al which showed highly significant difference found in the spirometric variables in obese and non-obese asthmatics. Our study also compared mean value of FEV1/FVC \% observed for the obese and nonobese groups which was $70.40 \pm 8.01$ and $65.03 \pm 7.34$ respectively. This finding is similar to the study done by Sharma et $\mathrm{al}^{20}$ whereas it is contrast with the findings of the study done by Dosi et al. The mean of FEF $25-75 \%$ in the present study among obese asthmatics is $1.31 \pm 0.62 \mathrm{l} / \mathrm{s}$ and in non-obese it is $1.59 \pm 0.76 \mathrm{l} / \mathrm{s}$. The values were lower compared to non-obese asthmatics which was comparable with the study done by Zied et al. ${ }^{21}$ Earlier studies showed (Sharma L, et al) the mean percentage change in reversibility of spirometric values in non-obese population highly significant, but our study shows the contrast.

\section{CONCLUSIONS}

- In this study, out of 100 patients $55 \%$ were males and $45 \%$ were females with higher total cholesterol and triglycerides in obese asthmatics was $(201.97 \pm 32.41$ $\mathrm{mg} / \mathrm{dl}$ and $147.48 \pm 61 \mathrm{mg} / \mathrm{dl}$ respectively) as compared to non-obese asthmatics $(172.27 \pm 25.03 \mathrm{mg} / \mathrm{dl}$ and $115.13 \pm 40.01 \mathrm{mg} / \mathrm{dl}$ respectively).

- Total cholesterol, triglycerides, HDL and VLDL were increased in Obese II asthmatic group compared to Obese I and at-risk asthmatic group.

- The most common symptoms were breathlessness followed by cough and wheeze.

- There was significant difference of waist circumference (W.C.), hip circumference (H.C) and waist to hip ratio (W.H.R.) between obese and non-obese asthmatics.

- Peripheral blood eosinophilia was higher in non-obese asthmatics $\left(600.72 \pm 300.96\right.$ cells $\left./ \mathrm{mm}^{3}\right)$ compared to obese asthmatics ( $449.5 \pm 246.16$ cells $/ \mathrm{mm}^{3}$ ) whereas total count was higher among obese asthmatics (10600 \pm 2381.05 cells $/ \mathrm{mm}^{3}$ ) compared to non-obese asthmatics (9310 \pm 1835.59 cells $/ \mathrm{mm}^{3}$ ).

- Moderate and severe grade of asthma were found to be slightly higher in the obese group (60\% and $23.33 \%)$ compared to non-obese group (46.67\% and $13.33 \%$ ) respectively, however, these values are not statistically significant.

- $\quad$ FVC, FEV1, and FEF25-75 \% values were reduced in obese asthmatics $(1.61 \pm 0.38 \mathrm{l} / \mathrm{s}, 1.13 \pm 0.24 \mathrm{l} / \mathrm{s}$ and $1.31 \pm 0.62$ $\mathrm{l} / \mathrm{s}$ respectively) compared to non-obese asthmatics ( 2.26 $\pm 0.88 \mathrm{l} / \mathrm{s}, 1.50 \pm 0.65 \mathrm{l} / \mathrm{s}$ and $1.59 \pm 0.76 \mathrm{l} / \mathrm{s}$ respectively) in contrast with FEV1/FVC which was higher in obese asthmatics $(70.40 \pm 8.01 \%)$ compared to non-obese asthmatics $(65.03 \pm 7.34 \%)$.

- Among obese asthmatics FVC values are much lower in Obese II compared to obese I and at-risk asthmatics. Whereas FEV1, FEV1/FVC and FEF 25-75 \% values are much lower among obese asthmatics compared to at risk and Obese II asthmatics.

- It was observed that increase in BMI causes impaired pulmonary function.

\section{REFERENCES}

[1] Global Initiative for Asthma (GINA). Global Strategy for Asthma Management and Prevention. Updated 2015. http://www.ginasthma.com (Accessed on June 22nd, 2015). 
[2] Hager A. Adipose tissue cellularity in childhood in relation to the development of obesity. Br Med Bull 1981;37(3):287-90.

[3] Visser M, Bouter LM, McQuillan GM, et al. Low grade systemic inflammation in overweight children. Pediatrics 2001;107(1):E13.

[4] Ford ES. The epidemiology of obesity and asthma. J Allergy Clin Immunol 2005;115(5):897-909.

[5] Global Health Observatory. Cited on 30/5/2015. http://www.who.int/gho/ncd/risk_factors/obesity_te $\mathrm{xt} / \mathrm{en} /$

[6] Rönmark E, Andersson C, Nyström L, et al. Obesity increases the risk of incident asthma among adults. Eur Respir J 2005;25(2):282-8.

[7] Park HS, Park JY, Yu R. Relationship of obesity and visceral adiposity with serum concentrations of CRP, TNF-alpha and IL-6. Diabetes Res Clin Pract 2005;69(1):29-35.

[8] Schwarzenberg SJ, Sinaiko AR. Obesity and inflammation in children. Paediatr Respir Rev 2006;7(4):239-46.

[9] Jones RL, Nzekwu MM. The effects of body mass index on lung volumes. Chest 2006;130(3):827-33.

[10] World Health Organization, Western Pacific Region. The International Association for the Study of Obesity and the International Obesity Task Force. The AsiaPacific Perspective: Redefining Obesity and its Treatment. Health Communications Australia Pty Limited, Sydney, Australia, 2000. www.wpro.who.int/nutrition/documents/docs/Redef iningobesity.pdf (Last accessed August 23 2015).

[11] Biring MS, Lewis MI, Liu JT, et al. Pulmonary physiologic changes of morbid obesity. Am J Med Sci 1999;318(5):293-7.

[12] Fredberg JJ, Inouye DS, Mijailovich SM, et al. Perturbed equilibrium of myosin binding in airway smooth muscle and its implications in bronchospasm. Am J Resp Crit Care Med 1999;159(3):959-67.
[13] Elmer PJ, Brown JB, Nichols GA, et al. Effects of weight gain on medical care costs. Int $\mathrm{J}$ Obes 2004;28(11):1365-73.

[14] Castro-Rodríguez JA, Holberg CJ, Morgan WJ, et al. Increased incidence of asthma like symptoms in girls who become overweight or obese during the school years. Am J Respir Crit Care Med 2001;163(6):1344-9.

[15] Dosi R, Veerapaneni VR, Bhaskar BV, et al. A study of spirometry in obese and non-obese asthmatics. Journal of Evolution of Medical and Dental Sciences 2013;2(8):903-20.

[16] Beuther DA, Sutherland ER. Overweight, obesity and incident asthma: a meta-analysis of prospective epidemiologic studies. Am J Respir Crit Care Med 2007:175(7):661-6.

[17] Aruna G, Kumar KS, Chandra N. Comparison of prevalence, clinical presentation and spirometry in bronchial asthma in obese and non-obese patients. Journal of Evolution of Medical and Dental Sciences 2015;4(58):10136-41.

[18] Pakhale S, Doucette S, Vandemheen K, et al. A comparison of obese and nonobese people with asthma. Chest 2010;137(6):1316-23.

[19] Razi E, Moosavi GA. The effect of positions on spirometric values in obese asthmatic patients. Iran J Allergy Asthma \& Immunol 2007;6(3):151-4.

[20] Sharma L, Putti N, Chaskar A, et al. To evaluate the influence of inhaled bronchodilator therapy on spirometric test variable in obese and non-obese asthmatics. Journal of medical and scientific research 2015;3(4):166-71.

[21] Rasslan Z, Saad R Jr, Stirbulov R, et al. Evaluation of pulmonary function in class I and II Obesity. J Bras Pneumol 2004;30(6)508-14. 